\title{
Ciência e política, ciência ou política: O ISEB e suas duas vocações
} Daniel Mano Gonçalves

\section{Daniel Soares Mano Gonçalves}

Doutor em Ciência Política pela UFF. Professor Iserj, Sesi e Lares/UFRJ.

Email: dan_soci@yahoo.com.br

ORCID: 0000-0001-9476-4279

\section{Resumo}

Neste artigo, examino a disputa teórico-metodológica, ocorrida no âmbito do Instituto Superior de Estudos Brasileiros (ISEB), entre duas concepções distintas do nacionaldesenvolvimentismo, personificadas por Helio Jaguaribe e Álvaro Vieira Pinto. Sustento que, mais do que apenas um debate sobre a natureza, os métodos e os objetivos do nacional-desenvolvimentismo, o debate contrastou duas posições sensivelmente distintas sobre a natureza do conhecimento político, a relação entre pensamento e ação e o papel ideal da intelligentsia isebiana na vida social e política nacional.

\section{Palavras chave}

Pensamento político brasileiro, ISEB, Nacional-desenvolvimentismo

\begin{abstract}
In this article, I examine the theoretical-methodological dispute between two distinct conceptions of national developmentalism, embodied by Helio Jaguaribe and Álvaro Vieira Pinto, within the scope of the Higher Institute of Brazilian Studies (ISEB). I maintain that, rather than just a debate on the nature, methods, and objectives of national developmentalism, the debate contrasted two perceptibly distinct positions on the nature of political knowledge, the relation between thought and action, and the ideal role of the Isebeian intelligentsia in national social and political life.
\end{abstract}

\section{Keywords}

Brazilian political thought, ISEB, National-developmentalism 


\section{Introdução: a ciência política enraizada}

A tradição de reflexão política no Brasil porta origens bastante longínquas, vinculadas à própria formação do Estado brasileiro. Como indica Lessa (2011:7), Pensadores como Frei Caneca, José Bonifácio e o Visconde de Cairú fizeram parte da constituição de uma esfera de avaliação e debate acerca das estruturas políticoinstitucionais estabelecidas no país, no curso do século XIX. Uma característica comum a esses intelectuais consistiu no fato de terem sido não somente pensadores da política, mas seus operadores - estadistas, políticos, líderes, uma classe muito próxima da prática, do calor dos acontecimentos, característica essa que pode ser observada, certamente, em agentes situados além dos limites do século XIX.

Lamounier (1982:411) observa que os pensadores antiliberais do início do século $X X$, preocupados com a questão da vertebração de um espaço público centralizado e ativo no Brasil, marcado então pela dispersão social e rarefação institucional - entre os quais Oliveira Vianna é, certamente, o mais conspícuo representante - não eram atores estritamente acadêmicos. Projetavam suas reflexões sobre a prática política, no combate às oligarquias arcaicas, e no fortalecimento das estruturas do Estado. Não eram necessariamente agentes diretos do Estado, mas suas análises orientavam-se à superação de dilemas políticos concretos, imediatos, prementes. Exemplo disso é a ação de Oliveira Vianna como consultor jurídico do Ministério do Trabalho, de 1932 a 1940. Sua colaboração no processo que culminou com a Consolidação das Leis Trabalhistas é relatada no Prefácio de seu livro Instituições Políticas Brasileiras, onde afirma que sua tarefa fora, basicamente, de conversão daquilo que denominou "Direito Público Costumeiro", distribuído em áreas como o direito social operário e o direito do trabalho marítimo, em leis. A experiência de Oliveira Vianna ilustra sua preocupação fundamental e de outros autores a ele contemporâneos, como Alberto Torres e Azevedo Amaral: a constituição e consolidação das instituições políticas modernas no país.

Com o gradual desenvolvimento de uma vida acadêmica substantiva no país, e o estabelecimento de instituições bem firmadas no espaço público - partidos políticos, eleições, um Estado centralizado e com poder efetivo de intervenção na sociedade - 0 pensamento político afasta-se, progressivamente das demandas imperiosas da consolidação do Estado Nacional. Nos anos do pós-guerra, as ciências sociais desenvolvem-se notadamente em dois prestigiosos centros: a USP e o ISEB. Mas a ciência política não alcança um estado de autonomia significativa, sendo antes ofuscada pela influência do pensamento sociológico europeu. Miceli (apud FORJAZ, 1997:2) observa: "[...] o currículo da faculdade paulista se nutria de uma alentada formação filosófica sobre a qual foi se erigindo progressivamente o predomínio intelectual da disciplina sociológica convertida em núcleo dinâmico da produção acadêmica". Lamounier (1982:417) vê o mesmo predomínio:

No que diz respeito à tradição paulista, o aspecto principal a registrar é que o crescimento das Ciências Sociais se deu até certo ponto contra a Ciência Política[...]Não se trata de discutir aqui o acerto ou não dessa orientação geral dos estudo sociológicos da USP. Afirma-se apenas que ela teve como consequência um sociologismo às vezes exagerado, na medida em que não dirigia a atenção para os temas propriamente políticos, ou político-institucionais. (LAMOUNIER, 1982:417).

A reflexão política, assim, deixa progressivamente o terreno da atividade inventiva, voltada aos desafios de construção e adaptação institucional. As instituições 
políticas nacionais passam a funcionar, aparentemente, sob lógica própria, obedecendo a imperativos intrainstitucionais, no âmbito de um processo de crescente burocratização. Essa autonomização de rotinas e métodos nas estruturas de Estado, contudo, não conduz imediatamente à autonomização correspondente da ciência política.

Libertado das vicissitudes da prática, o pensamento político encontra-se imerso na sociologia, disciplina há mais tempo estabelecida, tradicional e solidamente institucionalizada. É conveniente a analogia dessa proeminência com o conceito de embeddment (traduzido aqui livremente como enraizamento). Para Polanyi (2000), a economia é uma dimensão da atividade humana - um sistema de representações imerso em outros sistemas, como a moralidade, a religião, a política, etc. A tentativa de elevar a economia de mercado, nos moldes neoclássicos, a um sistema autônomo diante dos outros, "teria destruído fisicamente o homem e transformado seu ambiente num deserto" (POLANYI, 2000:4), caso a sociedade não houvesse posto em jogo seus mecanismos de auto-defesa, isto é, as reações sociais espontâneas ao radicalismo das experiências liberalizantes havidas no contexto da Revolução Industrial. Polanyi emprega o conceito de enraizamento para criticar o individualismo sem freios, aniquilador do tecido social. Transpondo o conceito ao domínio do conhecimento científico, é possível imaginar os problemas de uma ciência desenraizada de orientações morais, ou que ignore o interesse público. Embora a totalidade da ciência se encontre - salvo raros episódios históricos - moralmente enraizada, não a ponto de seu sufocamento, mas da demarcação de seus limites, entre os campos científicos não parece haver razões para que um deles obstrua o desenvolvimento de outro, isto é, não parece haver uma justificação epistemológica razoável, nos marcos da ciência contemporânea, para o enraizamento interdisciplinar - seja sociológico, biológico, psicológico, etc, isto é, para a consideração de uma "ciência primordial" a subordinar todas as outras.

No caso específico das ciências sociais, a sociologização das reflexões políticas obstou amiúde a consideração do fenômeno político, tomado em sua especificidade. Bloqueou, mesmo, a concepção das instituições políticas como capazes de algum impacto, de transformações substantivas no âmbito da cultura, constituindo apenas um pálido reflexo condicionado das infraestruturas culturais e econômicas. O domínio político parece sempre redutível a outros, e raras são as análises que o concebem em seus próprios termos. O predomínio do funcionalismo durkheimiano na Sociologia uspiana, pelo menos até a década de 60 , ensejou a concepção das instituições políticas como funções da sociedade. Conforme observou Candido:

A sociologia de Durkheim é uma espécie de cânone da Universidade de São Paulo, trazido pelos franceses a partir de 1934. Mas ela já tinha raízes aqui. Alguns sociólogos precursores, tal como Fernando de Azevedo, já estavam plenamente lançados na influência durkheimiana. (CANDIDO apud PEIRANO, 1990:42).

Mesmo nas obras de grandes intérpretes do Brasil da época insuspeitos de filiação à voga funcionalista podem ser encontrados elementos dessa subordinação da política, como é o caso de Sérgio Buarque de Holanda, não por acaso um intelectual vinculado à Escola de Sociologia e Política de São Paulo e posteriormente à USP.

No capítulo final de Raízes do Brasil, Buarque analisa as perspectivas de transformações politicas no Brasil, sempre referidas a transformações prévias, sociais e econômicas. Ao processo social de urbanização, por exemplo, corresponderiam as 
instituições republicanas, enquanto as soluções voluntaristas que ignorassem os condicionantes estruturais da cultura seriam inócuos, reformas "cosméticas", fadadas à perpetuação das estruturas arcaicas, agrárias e personalistas. As revoluções de quartelada, típicas da América Latina, consistiriam, dessa forma, em "um remédio aleatório, quando não precedida e até certo ponto determinada por transformações complexas e verdadeiramente estruturais na vida da sociedade" (HOLANDA, 2011:178). Os fenômenos políticos representam, assim, mais do que tudo, epifenômenos, objetos fugidios e inconcebíveis em sua singularidade.

Um levantamento realizado por Lamounier (1982:417) expressa em números essa submersão dos fenômenos políticos. De 37 teses de doutorado apresentadas na Pós-Graduação em Ciências Sociais da USP, de 1945 a 1964, apenas 13 poderiam ser classificadas como de Ciência Política, e mesmo assim, com importantes lacunas. Nenhuma abordou partidos políticos e sistemas eleitorais, por exemplo, que se tornaram objetos de interesse da área do direito, mais especificamente da Faculdade de Direito da UFMG, onde Orlando de Carvalho, em 1956 deu início à Revista Brasileira de Estudos Políticos, responsável por vultosa produção de material empírico relacionado ao sistema eleitoral brasileiro, à luz do direito constitucional. Schwartzman (1977:2) resumiu o status da ciência política brasileira ao longo do século XX: "A vinculação estreita entre a ciência política e o direito, por um lado, e à sociologia, por outro, fez com que esta disciplina custasse a adquirir, no Brasil, feição própria".

Convém destacar que esse enraizamento aqui caracterizado não configura um fenômeno exclusivo do pensamento político nacional. Cabral (1982) ao comentar o estado da arte da ciência política portuguesa, viu-a envolta, por força da ideologia salazarista, em um "casulo moral" (CABRAL, 1982:251) que fez do passado mítico português a referência quase obrigatória dos estudos políticos no país, pelo menos até o declínio do Estado Novo português, em 1974. Pensadores das mais variadas linhagens políticas puseram-se a examinar questões tais como a cultura seiscentista, o Sebastianismo e a remota conquista do Novo Mundo. Na tentativa de instrumentalizar o passado, as investigações alimentadas pelo pathos nacionalista sucediam-se sem benefício de um tratamento científico tanto da história como da política. Cabral indica ainda outros enraizamentos sob os quais o pensamento político se encontrou em Portugal - econômico, social, cultural, até a muito tímida e recente autonomização dos estudos políticos e sua institucionalização, com a criação dos cursos de Política do Instituto Universitário de Lisboa e da Universidade Nova de Lisboa.

Já sobre a ciência política americana, Forjaz observa que:

$$
\begin{aligned}
& \text { Mesmo nos Estados Unidos, onde o desenvolvimento } \\
& \text { acadêmico da Ciência Política foi mais intenso e precoce, esse } \\
& \text { processo significou uma longa batalha intelectual de } \\
& \text { construção de identidade disciplinar [...] durante muito tempo } \\
& \text { a política foi encarada naquele país como um "ramo" da ciência } \\
& \text { - mãe, da ciência-síntese, a sociologia (FORJAZ, 1997:3) }
\end{aligned}
$$

Lindblom (1998:245), ao comentar o prestígio das ciências sociais americanas nas décadas de 40 e 50, aponta para a relativa invisibilidade da ciência política, e sua dependência em relação a outros campos de saber. As grandes contribuições aos estudos políticos originavam-se, em grande parte da sociologia, da antropologia e da economia, através da teoria dos jogos e do estrutural-funcionalismo.

A subordinação da reflexão política a outros domínios, portanto, não foi exclusividade da realidade brasileira. Esse enraizamento pode ser creditado a muitos 
fatores, dentre os quais, talvez o mais duradouro tenha sido a notável dificuldade de se conceber um enfoque próprio à ciência política, uma moldura epistemológica que não tomasse de empréstimo as teorias e métodos consagrados em outros campos. Não tardou, tanto no contexto brasileiro quanto alhures, para que o pensamento político encontrasse seus objetos - o Estado, os partidos, os entes de poder em geral, e aqueles em sua órbita. Esse compromisso ontológico já estava presente nas reflexões do início do século XX no Brasil. Quanto à epistemologia, porém, reinou um vazio preenchido, ora pela sociologia, ora pelo direito.

As características de uma ciência da política concebida como acervo de perspectivas teóricas originais estiveram presentes, curiosamente, fora da esfera acadêmica propriamente dita, em um espaço ocupado, como veremos a seguir, pelos intelectuais ligados ao ideal do nacional-desenvolvimentismo, um grupo que, ao dirigir o olhar para as instituições políticas existentes, além de elevá-las ao proscênio de suas inquirições, ocupou-se de relacioná-las, ecleticamente, à ideia do bem comum, em legitimá-las ou deslegitima-las, como elementos responsáveis pelo atraso ou o progresso nacional.

\section{As ciências políticas do ISEB}

O pensamento político no Rio de Janeiro dos anos 1950 e 60 tinha endereço certo: a esfíngica nona mansão da Rua das Palmeiras, o Instituto Superior de Estudos Brasileiros (ISEB). Encravado na pequena rua de Botafogo, o ISEB, criado por decreto presidencial em 1955 sucedeu o informal Grupo de Itatiaia e o Instituto Brasileiro de Economia, Sociologia e Política (IBESP), criados três e dois anos antes, respectivamente, por intelectuais paulistas e cariocas. Propunha-se a construir um edifício teórico de bases nacionalistas para interpretação e ação, no sentido de colaborar com as transformações necessárias ao desenvolvimento social e econômico do país. Funcionou, a princípio, como aglutinador de disciplinas e visões de mundo bastante diversas e dispersas. Sua estrutura inicial incluía um Conselho Consultivo, composto por 50 membros representativos dos diversos saberes e matizes ideológicos, do qual faziam parte intelectuais como Sérgio Buarque de Holanda, Gilberto Freyre, Roberto Campos, Miguel Reale, San Tiago Dantas, Augusto Frederico Schmidt e Sergio Milliet.

Há, hoje, uma relativa fortuna crítica em relação ao ISEB, da qual me valerei para, de forma breve, traçar seus aspectos mais gerais, e esclarecer as condições nas quais a ciência política se desenvolveu no interior da instituição. Os departamentos do ISEB, responsáveis pelas publicações e cursos regulares eram cinco: Filosofia, História, Economia, Sociologia e Ciência Politica, inicialmente sob a responsabilidade inicial, respectivamente, de Álvaro Vieira Pinto, Cândido Mendes, Evaldo Correa Lima, Guerreiro Ramos e Hélio Jaguaribe.

É difícil a tarefa de caracterizar a ciência política isebiana, diante da matéria aparentemente indistinta que as disciplinas compunham no interior do instituto. Havia, certamente, uma aproximação entre os cinco departamentos que dificilmente se encontra nos tempos atuais, com a crescente valorização do saber especializado, cioso de delimitar com clareza seu raio de incidência reflexiva. Ainda assim, podem ser observadas certas marcas inerentes a cada campo, em inspeção detalhada. Uma sutileza, como um conceito, uma figura de estilo ou uma interrogação pode indicar a orientação predominante em cada departamento. Jaguaribe, titular da ciência política, por exemplo, enfatizava com frequência as soluções técnicas para as crises do subdesenvolvimento, orientadas a padrões de eficiência, e, portanto, punha em 
destaque o papel ativo das instituições de Estado, tendência que Pécaut (1990:119) caracteriza como "tecnocrática" ou "neobismarckiana", devido à ênfase contínua no planejamento racional para se alcançar o desenvolvimento - inclusive através da socialização dos meios de produção, como Jaguaribe sustentou nas páginas dos Cadernos do Nosso Tempo. Guerreiro Ramos, por sua vez, era bastante explícito em suas categorizações sociológicas, tais como a "consciência ingênua" e "consciência crítica", que dialogam com a tradição conceitual da sociologia européia, transportandoas, porém, às referências históricas da realidade nacional, no bojo de sua tentativa de elaborar uma "sociologia nacional" (PÉCAUT, 1990:120).

Áreas de conhecimento em constante diálogo, um corpo docente e colaborador amplo, representativo e de notório saber. Tudo conspirava no sentido de transformar o ISEB em um pólo científico sem par no Brasil. De fato, como observa Pécaut (1990), sua vocação inicial parecia ser a de consolidar-se como um centro de altos estudos, nos moldes da Escola Superior de Guerra, ao qual era frequentemente comparado, porém conduzido por civis. Mas um fator afastou-o definitivamente da institucionalização nos moldes acadêmicos tradicionais, como centro direcionado, de forma precípua, ao tripé ensino/pesquisa/extensão. Trata-se da imersão de todos os saberes em uma concepção compartilhada do nacional-desenvolvimentismo. Houve, no nacional-desenvolvimentismo isebiano mesmo uma repulsa à idéia de consolidação de uma ciência objetiva, explicitada por Guerreiro Ramos, ao criticar a tradição empirista norte-americana nas ciências sociais: "É esse empirismo que transparece na tentativa dos que pretendem elaborar a compreensão de uma sociedade nacional por meio de mera coleção de fatos, estudos monográficos de comunidade, 'surveys ' locais, como se desse material bruto se pudessem extrair categorias compreensivas" (RAMOS apud TOLEDO, 1982:61)

É possível afirmar que o nacional-desenvolvimentismo esteve presente desde sempre no horizonte do ISEB, e já o estava em seus embriões, o Grupo de Itatiaia e o IBESP. Mas houve uma gradual transformação, ao longo dos anos, fazendo de um ideal regulatório algo difuso, um ideal claro e hegemônico dentro do instituto, mais e mais vívido e próximo da atividade política, da militância.

Uma das formas possíveis de se narrar a história do ISEB consiste em investigar a construção lenta e contínua desse comprometimento que se formou em torno de uma concepção bastante paradoxal do nacional-desenvolvimentismo: fluida e firme, ambígua e resoluta, lírica e concreta. A história do ISEB pode ser dividida em três períodos: o $1^{\circ}$ e mais curto, que vai de 1955, ano de criação do ISEB, até o ano seguinte, com a posse de Juscelino Kubitschek, o $2^{\circ}$ e mais longo, que abrange 0 qüinqüênio de Juscelino, e o último, que começa a tomar forma com o fim da Era Juscelino, e o início das discussões em torno das Reformas de Base. A esses três períodos corresponderam, como assinala Pécaut (1990:107), diferentes modelos de síntese teórica: o nacional-desenvolvimentismo, o nacional-populismo e o nacionalmarxismo.

No $1^{\circ}$ período e boa parte do $2^{\circ}$, é possível observar a heterogeneidade dos posicionamentos dentro da instituição, pelos próprios nomes que formam seu Conselho Consultivo. Esse ecletismo evoca a herança de experiências anteriores, como o Grupo de Itatiaia, a seguir-se a análise de Pereira, para quem "o grupo[de Itatiaia] formado tinha como característica a existência de diferenças teóricas, ideológicas e políticas entre seus componentes [...] Trata-se, também, de uma geração de intelectuais que 
vivenciou distintas experiências políticas, sobretudo, na década de 1930" (PEREIRA, 2002:140).

Esse trecho remete à aproximação de muitos intelectuais do Grupo a movimentos tão díspares como o integralismo, com o qual Roland Corbisier e Guerreiro Ramos flertaram na década de 1930, e o socialismo, caso de Ignacio Rangel, que chegou a integrar o PCB e a Aliança Nacional Libertadora. O Grupo de Itatiaia, portanto, é marcado não apenas por diferenças de ordem intelectual; são trajetórias existenciais bastante heterogêneas que o compõem. Representantes de quase todos os matizes ideológicos e campos de saber, portanto, desembarcam na formação inicial do ISEB, alguns deles, inclusive, abertamente antinacionalistas, como as tendências antiestatistas e tecnocráticas, cujo representante mais notório foi, certamente, o economista Roberto Campos. O próprio nacionalismo, tendência dominante no $2^{\circ}$ período, não foi consensual, principalmente no que diz respeito à concepção da relação entre pensamento e ação, como veremos adiante.

O conceito clássico, marxista, de ideologia seria, por certo, insuficiente para uma análise do nacional-desenvolvimentismo isebiano. Da mesma forma que o conceito de alienação, o de ideologia, no ISEB, foi submetido a uma releitura bastante heterodoxa do conceito original , heterodoxa a ponto de tornar-se possível, segundo a conceituação de Helio Jaguaribe, a existência uma "ideologia autêntica" oposta às "ideologias representativas". Jaguaribe define a ideologia como:

[...] o conjunto de valores e de idéias que apresentam como razoável e desejável determinado projeto ou estatuto convivencial para a comunidade, a partir dos interesses situacionais de determinada classe ou grupo social. São os interesses situacionais, ou seja, os que decorrem de uma situação social suficientemente caracterizada e geral, como as situações de classe, que determinam o projeto de estatuto convivencial [grifo nosso]. (JAGUARIBE, 1958:48-49).

E, depois, acrescenta:

Nem sempre as aspirações sociais de determinada classe correspondem a seus interesses [...]. Na medida em que isso não ocorre, as classes ideologicamente mal-orientadas tendem a sofrer as consequências da inadequada formulação de suas aspirações, tornando-se vítimas da própria ideologia e perdendo a oportunidade de organizar em função dela a sociedade a que pertencem. (JAGUARIBE, 1958:49).

Quando referida exclusivamente ao interesse de uma classe específica, a ideologia seria representativa. A autenticidade, contudo, só pode ser conferida quando a ideologia representa, junto a um interesse de classe qualquer, o interesse geral da sociedade, seu encaminhamento na direção da superação da fase em que essa civilização se encontra. A conceituação de Jaguaribe sugere a ação de uma intelligentsia, capaz de transcender seus interesses estreitos de classe e realizar a "síntese" referida por Mannheim:

Devemos a possibilidade de interpretação mútua e compreensão das correntes de pensamento existentes à presença desse estrato médio relativamente desvinculado que se encontra aberto ao ingresso constante de indivíduos das mais diversas classes e grupos sociais, com todos os pontos de 
vista possíveis. Só nessas condições pode surgir a síntese incessantemente nova e ampla a que nos referimos". (MANNHEIM, 1986:186).

Jaguaribe e os demais intelectuais do ISEB pareciam estar de acordo quanto à adequação dos intelectuais isebianos ao papel desta intelligentsia, capaz de conciliar os interesses da burguesia nacional com as diretrizes mais amplas do desenvolvimento nacional.

A preocupação com a ação política foi uma marca de distinç̧ão do ISEB. Essa preocupação esteve presente, de certa forma, na arquitetura do instituto, em sua rejeição ao academicismo e à burocratização. A imersão das cinco disciplinas na ideologia e na prática nacional-desenvolvimentista dificultou a constituição de um corpo científico detached, calcado em ideais de objetividade científica e regido por critérios internos a cada disciplina. Prejudicou a formação de um ethos acadêmico clássico, que constituiria uma espécie de entrave ao engajamento, diante da ritualística típica das burocracias universitárias.

$O$ acento nacional-desenvolvimentista do ISEB foi dinamizado pela ideia, defendida por Jaguaribe, de que cabia à instituição o papel de intelligentsia. Não que esse papel fosse incompatível com o do cientista social detached, do acadêmico profissional, tal como se encontrava, principalmente, na USP à época. Mas a prioridade, inspirada, talvez, em um sentido de ordenação histórica - ou de fase histórica, jargão do instituto - era sem dúvida a da ação, da transformação estrutural da sociedade, sem a qual os campos científicos autônomos poderiam ser vítimas de si mesmos, da irrelevância, da tibieza e da influência muito indireta sobre a sociedade e os órgãos do Estado. Quanto a essa "missão", pouca era a divergência: o modelo do instituto deveria dar conta da premência do desenvolvimento. Dizendo de outro modo, para que a academia tivesse alguma possibilidade de se transformar em uma autêntica intelligentsia, era necessário o engajamento não-acadêmico dos intelectuais. Ao colocar-se frontalmente contra um conjunto de obstáculos arcaicos - as oligarquias, a classe média improdutiva, etc -, o ISEB via-se, ironicamente, como o agente que poderia tornar a comunidade científica relevante, como o vertebrador de uma sociedade permeável ao discurso científico. E é talvez esta característica que mais tenha aproximado seus intelectuais daqueles intelectuais brasileiros que, no início do século $\mathrm{XX}$, ansiavam por dar forma à sociedade civil, através da atividade indutiva e ostensiva do Estado.

O ecletismo dos anos iniciais representava, cada vez mais, uma espécie de obstáculo epistemológico para os membros do instituto. O desejo de transformações esbarrava na carência de uma orientação geral clara, e se as posições tão díspares observadas entre os colaboradores casuais não era tanto o problema, havia uma oposição fundamental e decisiva para o destino do ISEB, entre duas faces de seu núcleo, que acabou tornando-se mais aguda no choque entre dois de seus mais influentes intelectuais: Helio Jaguaribe e Álvaro Vieira Pinto. O primeiro, por força de sua liderança, que remonta aos tempos do Grupo de Itatiaia e do IBESP, sintetizava um conjunto de ideias presentes no pensamento de grande parte dos "isebianos históricos", como Guerreiro Ramos, Roland Corbisier e Cândido Mendes, principalmente quanto ao papel de intelligentsia a ser desempenhado pelos intelectuais do instituto. Jaguaribe, no entanto, deu um passo além, que mais do que isolá-lo, tornou explícitos os posicionamentos dos componentes do grupo. 
As idéias de Álvaro Vieira Pinto destoaram, desde o início, das dos demais isebianos. Enquanto Jaguaribe e os demais atribuíam à vanguarda intelectual o papel de artífices da ideologia do desenvolvimento e condutores privilegiados desse processo, Vieira Pinto concebia a intelectualidade como porta-voz, como articuladora dos interesses e da ideologia forjada na própria consciência das massas. Não há em Vieira Pinto o gap entre aspirações e interesses de classe a que Jaguaribe se refere, pois a massa não é ignorante de seus interesses. Estes podem, quando muito, se manifestar de maneira rudimentar e desordenada, e a incumbência da intelligentsia deveria ser de esclarecimento desses interesses, nunca de revelação. Cortes (2005:124) define esse posicionamento como "igualitarismo cognitivo", a noção sempre presente nas obras do filósofo de que as massas e a assim chamada elite intelectual compartiam a capacidade de desenvolver um modo crítico e autêntico de consciência.

Jaguaribe e os demais se distanciam de Vieira Pinto, assim, pela via da composição dos conceitos. Forjar o nacional-desenvolvimentismo, em Jaguaribe, Corbisier, Cândido Mendes e Guerreiro Ramos significa forjar conceitos, ou, para ser mais exato, adaptar os conceitos consagrados pelas tradições intelectuais às quais se filiam, à conjuntura histórica e social da unidade fundamental da análise: a nação. Fazse mister que não se confunda, contudo, o conceitualismo desses autores com alguma espécie de metafisica pura, de sistematizacão abstrata tout court. O conceito de alienação, por exemplo, ganha certo protagonismo na narrativa construída pelo ISEB, mas não no sentido clássico, de servidão do trabalho a sua própria objetivação no capitalismo, tal como encontrado nos Manuscritos Filosófico-Econômicos do jovem Marxi, e sim ressignificado pelo par de categorias considerado mais apropriado à apreensão do momento histórico brasileiro: nação e antinação. Surge assim um conceito atrelado a um cenário de atraso, subdesenvolvimento e dependência no concerto das nações, o conceito de nação alienada. Corbisier (1959:79-80) rejeita textualmente o materialismo-histórico, propondo em seu lugar uma dialética entre ideia e matéria. Demarca seu posicionamento epistemológico como da "totalidade", em que as estruturas econômica e ideológica são elementos de composição. A nação, nessa chave, é entendida como um "fenômeno social global". O argumento de Corbisier, resgatando o peso das ideias na História, resulta, em última análise, no realce à ação dos intelectuais como agentes ideológicos, à maneira de uma intelligentsia mannheimiana.

\section{Pensamento e ação}

A polarização entre os dois núcleos, e cada vez mais entre as ideias de Jaguaribe e Vieira Pinto tem sua face mais visível no que diz respeito aos desacordos em torno das relações entre pensamento e ação. O vago nacional-desenvolvimentismo que a todos unia, mesmo que sob tantas particularidades, não logrou sustentar-se diante desse desacordo fundamental. De um lado, as produções do pensamento político tornam-se, pretensamente, independentes da ação, autônomas e divisíveis. 0 lugar do nacional - desenvolvimentismo na obra de Jaguaribe não é de um sistema que abarque a vida, mas de um projeto tolerante a muitos meios, uma obra em progresso, posto que concebido como um fim cujos meios empregados para alcança-lo não o alteram necessariamente, não imprimem suas marcas de forma indelével. Seria um engano, por outro lado, enxergar em Vieira Pinto a marca do misticismo ou do dogma, pois sua teoria confere centralidade às mudanças, às transformações, ao curso concreto e acidentado da História. Mas, à diferença de Jaguaribe, a nação não constitui um fim, um ideal regulatório; antes, ela é sentida e intuída, e pensa-se através dela. A 
unidade da ação e da prática, prescrição e descrição e dos meios e dos fins não permite que se refira, pois, a um projeto racional de nacional-desenvolvimentismo na obra de Vieira Pinto, mas a um processo imanente de sua construção.

A concepção do papel que caberia ao ISEB, na perspectiva de Jaguaribe, pode ser interpretada a partir da chave da divisão entre pensamento e ação. Em entrevista a Pereira, ele afirma ter dito à época que:
O ISEB não tem nenhuma capacidade de se tornar um centro ativista importante. Vai ser um grupozinho de gente exaltada, querendo fazer coisa além dos seus recursos. Enquanto que se o ISEB mantiver a linha de uma intelligentsia como eu preconizo, a sua influência é extraordinária. (PEREIRA, 2002:165).

A preocupação de Jaguaribe recaía justamente sobre os rumos do ISEB, no sentido de um maior engajamento, de um enraizamento progressivamente mais agudo, de uma ideologia totalizante que conquistava cada vez mais adeptos, como é o caso de Guerreiro Ramos, que flertava com a tese de que cabia à instituição uma participação mais ativa no cenário político nacional. Na mesma entrevista acima citada, Jaguaribe afirma ter dito, em conversa com Guerreiro Ramos: "Somos formuladores de ideias [...] úteis para aqueles que estão na vida prática militante". (PEREIRA, 2002:164) Essa fala expressa a ideia de que entre ação e pensamento não há um vínculo ontológico, mas uma relação pragmática. As idéias servem aos operadores da prática política ordinária e essa prática serve aos elevados ideais da intelligentsia. Temse uma distinção tácita entre idéias (referidas à prática ordinária da política) e ideais visões últimas de mundo, ou aquilo que Weber (1996:137-142) denominou "ética de últimos fins", pólo contrário da "ética de responsabilidade". O lugar do pensamento é limitado à delimitação, observação e explicação dos fenômenos políticos, tendo em vista a relação entre meios e fins, observando-se os imperativos científicos de rigor e objetividade. O desenvolvimento nacional, como objeto de ciência, deve assumir, assim, a condição de um valor objetivo, existente na realidade e, enquanto tal, passível de investigação desapaixonada.

Em 1958, Jaguaribe lança O Nacionalismo na Atualidade Brasileira, livro de grande repercussão, no qual são sistematizadas as ideias que 0 autor vinha desenvolvendo sobre a situação do nacional-desenvolvimentismo. Trata-se de um marco não só da história do ISEB, mas do pensamento político brasileiro, que ganha uma notável referência normativa e epistemológica. Diante das polêmicas suscitadas pelo livro, Jaguaribe passa a ter que "prestar contas" quase que diariamente de suas ideias, e a oposição à doxa isebiana torna-se incontornável. A tal ponto que uma reunião é convocada, em dezembro de 1958 pelo Conselho Curador do instituto para debater o "Caso Jaguaribe".

O livro apresenta uma crítica enfática às confusões semânticas em torno do conceito de nacional-desenvolvimentismo, e uma tentativa de conferir-lhe contornos mais bem definidos, através do estabelecimento de pares de oposições, e da investigação da dinâmica a elas inerentes - a dialética. A análise do nacionalismo, assim, considera-o sob duas chaves iniciais: a objetiva e a subjetiva. A primeira, dizendo respeito a aspectos sociais, tais como os vínculos culturais, a geografia, a estrutura produtiva, e a segunda ao papel da vontade coletiva, do voluntarismo político. O fenômeno da formação das nações é compreendido a partir da interação 
entre as condições objetivas e o desenvolvimento do propósito, da vontade de agregação sob um mesmo estatuto jurídico-político.

É insuficiente, portanto, o processo histórico espontâneo para a formação das nações - deve haver um componente projetivo, instrumental. A nação, para Jaguaribe é basicamente projeto, no que se distancia bastante da concepção de Vieira Pinto, para quem o estabelecimento do sentimento nacional é um processo. O caráter deliberativo e estratégico do nacionalismo é insistentemente abordado por Jaguaribe. Em um mesmo parágrafo, ao discorrer sobre a gênese das nações, são consideradas condições prévias um "projeto político", um "projeto de vida nacional" e um "projeto de integração nacional" (JAGUARIBE, 1958:20). A Nação, portanto, é um conceito finalista, um horizonte, e como tal, não deve comportar contradições. Jaguaribe identifica, porém, diversas incongruências na prática corrente do nacionalismo e a vagueza que obscurece o sentido do fim a que se refere.

A vagueza criticada por Jaguaribe o impele a um esforço de caracterização da finalidade nacionalista, e neste ponto, tem-se uma importante fragmentação, entre os dois termos "nacionalismo" e "desenvolvimento": o nacionalismo passa à condição de meio, cuja finalidade é o desenvolvimento (econômico, cultural, político). Esta, certamente é a tese mais polêmica do livro, responsável pela maior parte dos questionamentos levantados posteriormente, principalmente pela aceitação explícita ao capital - cultural, inclusive - estrangeiro. 0 "nacionalismo instrumental" seria o resultado da formulação racional da questão, em termos de eficiência e rigor. Ao problema econômico específico da ausência de poupança interna, é recomendada a abertura regulada aos investimentos externos, e Jaguaribe, algo hereticamente, afirma que "[...] a política nacionalista do petróleo poderia ser realizada pela Standard" (JAGUARIBE, 1958:52). Tanto os meios como os fins, entretanto, conservam um sabor de contingência, de inacabamento da obra. É de bom alvitre que se leve sempre em consideração a concepção histórico-dialética de Jaguaribe e sua sucessão de fases. Os meios e fins a que ele se refere são situacionais e inserem-se em parâmetros históricos de adequação. Não só os meios, portanto, mas a própria finalidade do desenvolvimento é contingente e descortina as possibilidades de outras finalidades dormentes. A tarefa reservada à ciência política, ao que tudo indica, é de investigação sobre a adequação entre meios, fins e fase histórica.

Outro aspecto notável da obra é que nela está exposta a crença de que às contradições estruturais - econômicas, sociais, culturais e políticas - por que passam as sociedades, correspondem impasses ideológicos, e o nacionalismo caleidoscópico e difuso, deixado a si mesmo, à indefinição das massas seria uma dessas manifestações de contradições aparentemente insuperáveis. O desafio da superação - da síntese -, a elaboração do grande projeto de nação e de uma ideologia autêntica caberia, como aqui exposto, à vanguarda intelectual, colocando em movimento o componente subjetivo/voluntarista da dialética das nações. A rejeição ao espontaneísmo das massas como agentes de síntese é evidente em muitos momentos, e Jaguaribe a elas refere-se com frequência, às "mentalidades mais rudimentares e incultas [tendentes] a erigir a própria condição em ideologia" (JAGUARIBE, 1958:35), e aos proletários, que "ao investirem contra o regime de espoliação e privilégios de classe, fazem-no na forma de manifestações inorgânicas e inconsistentes do populismo" (JAGUARIBE, 1958:41). A intelligentsia, ao forjar uma ideologia autêntica, ou seja, global, válida para toda a comunidade e portanto não contraditória, evita o grande risco em que incorrem as ideologias populares, de reduzirem-se a ideologias de classe, em cujo 
interior, os agentes do atraso e do desenvolvimento combinam-se causando o pior dos cenários: a estagnação.

A reação às ideias de Jaguaribe foi quase imediata, e em alguns casos, exterior ao círculo isebiano, como no caso do pedido de esclarecimentos públicos enviado pela UNE, mas para os propósitos desta pesquisa, a mais relevante e contundente reação foi intelectual, a de Vieira Pinto, em seu monumental Consciência e Realidade Nacional, de 1960, que torna franca a oposição ensaiada desde o início das atividades do instituto entre a tendência "pragmática" e a tendência "holista", de Vieira Pinto. Na obra, o filósofo dirige-se a Jaguaribe nos seguintes termos:

\section{[...] tentam [os adversários do nacionalismo] introduzir em lugar da correta distinção entre fatos e sentido uma outra, errônea e maldosa, a distinção de nacionalismo de fins e nacionalismo de meios. Mas enquanto a primeira coloca a definição do caráter nacionalista da ação no sentido que lhe é dado pela consciência social que reflete as condições históricas do momento e tem na reação popular um índice praticamente infalível da sua verdade, a outra é maliciosa pois transfere o sentido para fins remotos dos atos, e não o faz coincidir com o conteúdo destes. [...] É possível dizer que a distinção citada se traduz praticamente por esta outra: nacionalismo de fins e entreguismo de meios. (PINTO apud TOLEDO, 1982:138-139).}

A crise em torno do livro de Jaguaribe foi reveladora de seu isolamento no instituto e da inflexão por que passou o posicionamento de outros intelectuais, notadamente Roland Corbisier e Guerreiro Ramos, que consideravam necessário acentuar o caráter crítico e ativista do ISEB, tornando ação e pensamento mais e mais indistintos. O resultado da crise é a saída voluntária de Jaguaribe do instituto, com o remanejamento de Cândido Mendes para o Departamento de Ciência Política. Curiosamente, Guerreiro Ramos, um de seus contendores, deixa a instituição no mesmo ano, afirmando que o ISEB tornara-se uma "escola de marxismo-leninismo" (RAMOS, 1963:10).

A guinada do ISEB no pós-crise, portanto, não foi apenas negativa - no sentido de repúdio às ideias propostas por um de seus criadores. Foi também responsável por um movimento centrípeto, que afastou a pluralidade epistemológica característica do instituto em favor da unidade da ação. No ano seguinte à crise, 1959, o grande símbolo de pluralidade, o Conselho Consultivo, cujo ecletismo foi aqui enfatizado, é extinto pelo Decreto Federal 45. 811. Em seu lugar, é criada a Congregação, composta pelos chefes dos cinco departamentos, que passam a ter funções como "supervisão das atividades docentes; exame de textos a serem editados; o convite a conferencistas e professores; a instituição de concursos e bolsas" (PEREIRA, 2002:156). Assim, o ISEB equipou-se para sua guinada em direção ao engajamento político.

Esse novo ISEB ampliou seus contatos com a sociedade, exteriorizou-se, multiplicou seus cursos extraordinários, e teve em Álvaro Vieira Pinto sua figura de proa, e que mais inspirou suas ações, principalmente após a saída, em 1961, de outros isebianos de primeira hora: Corbisier e Cândido Mendes. A direção executiva, a partir desse ano, ficou nas mãos de Vieira Pinto, até o fechamento do instituto, em 1964, mas sua influência maior pode ser observada no papel de artífice teórico da instituição.

$\mathrm{Na}$ aula inaugural do Curso Regular de 14 de maio de 1956, transcrita e editada com o título de Ideologia e Desenvolvimento Nacional, Vieira Pinto critica a estreiteza das visões finitas da realidade nacional, propondo em seu lugar o ponto de vista do 
infinito. A perspectiva de Vieira Pinto consiste em pensar a nação em um plano além da realidade observável e da consciência meramente sensitiva. No lugar da nação como artefato, propõe-se a nação como meio de se compreender e sentir a realidade, dotando-a de significado. É certo que o nacionalismo deve dirigir-se a uma finalidade rigorosamente definida, mas sempre parcial, como um fundo falso, pois a finalidade nacionalista não é um objeto a ser possuído, é um valor a ser conservado com a devida intensidade, sob constante exame público, pois, não obstante o aparente oxímoro, o fim não é mais conteúdo da finitude; por isso, Vieira Pinto observa que "sem a autenticidade da escolha inconveniente, não é possível a autocorreção da consciência pública" (PINTO, 1959:48).

Não basta, pois, a constatação da infinitude - deve-se imergir nela, aceitá-la como fundamento da sociabilidade e, como consequência, afirmar o diálogo como pedra de toque da construção coletiva da realidade nacional, não mais algum substrato oculto (CORTES, 2005). Teria faltado a Jaguaribe, desse ângulo, a ideia de unidade, do nacionalismo como um todo orgânico. Faltara-Ihe o predicado da sentença de Vieira Pinto: "o homem que possui uma idéia é ao mesmo tempo um homem possuído por essa idéia" (PINTO, 1959:20). A postulação de meios técnicos e eficientes para se alcançar o desenvolvimento, desse ponto de vista, é absolutamente insuficiente, caso não seja acompanhada de um ethos, da nação como sistema de representações da massa, profundamente enraizado. O nacionalismo, entendido como processo, não permite estratégias tópicas, parciais, que dêem conta de um problema de forma isolada, sem articulação com o problema maior da nação. O poeta Fernando Pessoa pode ser invocado, em um verso que parece conter a divisa dessa organicidade: "Sê todo em cada coisa. Põe quanto és / No mínimo que fazes" (PESSOA, 1996:117).

Nesse sistema, à intelectualidade fica reservada a função de conferir forma lógica à representação primitiva do nacionalismo das massas - transformar sentimentos em conceitos. Os últimos devem sempre referir-se aos primeiros, pois, do contrário, há o risco daquilo que Vieira Pinto chamou de "divagação doutrinária, mística social, onirismo político" (PINTO, 1959:22). O fundamento do nacionalismo é, portanto, o interesse público, que se torna cada vez mais claro à medida que as massas passam a fazer parte do circuito do trabalho e do progresso material. A tomada de consciência, em Vieira Pinto, diz respeito à nação e não à classe, e esse processo deve ser acelerado e corrigido, quando necessário, pela intelligentsia. Como fiadora da autenticidade da ideia da nação, e sua superioridade em relação a outras formas de identidade coletiva, como a classe, Vieira Pinto indica a força e a coerência da idéia de nação, que é capaz de fixar-se no espírito das massas de forma mais perene e vivaz do que as paixões violentas suscitadas pelas artimanhas da retórica e do carisma. O filósofo contemporâneo Nelson Goodman, ao comentar os critérios de decisão sobre a verdade e a falsidade das visões de mundo conflitantes afirma:

Em vez de falar de imagens como verdadeiras ou falsas, poderíamos falar melhor de teorias como certas ou erradas; pois a verdade das leis de uma teoria é apenas uma característica especial e é freqüentemente [...] sobrepujada em importância pela consistência e compactividade e abrangência, a informatividade e o poder organizador de todo o sistema. (GOODMAN, 1978:19).

A ideia de nação, assim, pode ser pensada como a mais adequada, para Vieira Pinto, em função de sua consistência, de sua adequação à condição histórica da massa e de sua capacidade de promover e consolidar, como instituição, os desígnios gerais de 
um povo, não por constituir um "princípio ontológico" ou "quintessência substantiva" (CORTES, 2005:129) da nação.

\section{Considerações finais}

O ISEB, sob a direção intelectual de Vieira Pinto, torna-se uma instituição engajada politicamente. Esse engajamento, entretanto, não deve ser compreendido como confinado às instituições políticas tradicionais - o Estado, os partidos e demais instituições integrantes da arena consagrada às disputas pelo poder. O ISEB e 0 nacionalismo orgânico de Vieira Pinto tornam-se referência na literatura, no teatro, na educação, enfim, na vida cultural do país. Aproxima-se da União Nacional dos Estudantes e de seus CPC's (Centros Populares de Cultura), do Teatro de Arena e, no espectro político, do Partido Comunista Brasileiro. Os principais intelectuais dessa fase, além de Vieira Pinto, são Wanderley Guilherme dos Santos, Carlos Estevam Martins, Nelson Werneck Sodré e Osny Duarte Pereira, este último, no comando da cátedra de Ciência Política. O ISEB, nessa etapa, torna-se alvo de intensa campanha por parte de seus adversários no campo conservador, e vê-se privado dos recursos de que gozava até então:

Privado do seu financiamento essencial, condenado a reduzir suas atividades de ensino e de publicação, associa-se à agitação em favor das reformas de base e participa da redação de diversos Cadernos do Povo, fascículos lançados pela editora Civilização Brasileira e que visam a colocar, em linguagem simples, as grandes questões do momento. (PÉCAUT, 1990:113).

A projeção da concepção de Vieira Pinto, do nacional-desenvolvimentismo orgânico, não implica no encapsulamento do ISEB por uma ideologia dogmática, estacionária, não é disso que se trata. Como indicado algumas páginas atrás, o aspecto imanente do nacional-desenvolvimentismo de Vieira Pinto contempla a ação, a prática e o engajamento unidos à teorização, indistintos, por assim dizer, e por isso mesmo, a teoria nacional-desenvolvimentista se faz dinâmica, capaz de progressos teóricos conjugados à intervenção social, estética e política.

Convém não se confundir, porém, o tipo de ação levada a cabo pelo instituto com a ação política ordinária. Mesmo próximos da política cotidiana, os isebianos desse último período não compartilham o ponto de vista estrito do homem de ação, do partisan, pois sua orientação visa transcender o partidarismo e o calor das refregas, integrando-os à teoria. Segundo Pereira (2002:220)
A sua opção [de engajamento político] os insere, ainda mais, na condição de intelectuais, na medida em que se tornaram fornecedores da síntese necessária aos envolvidos nas lutas dos movimentos populares nos anos 1960. Por essa razão, venho insistindo que o papel dos intelectuais do ISEB é, ainda nos anos 1960, o de uma intelligentsia no sentido dado a esse termo por Karl Mannheim. (PAREIA, 2002:220).

Nessa sua última fase, de maior engajamento, a figura de proa da ciência política isebiana foi Osny Duarte Pereira. Em Jaguaribe, era latente a tentativa de afirmação da ciência política, como um sistema de representações desvencilhado do nacionalismo orgânico. Havia um desejo de falar "sobre" a política, de torná-la objeto de investigação positiva. Osny Duarte Pereira representa um momento em que essa 
tensão fora dissipada, e o Departamento de Ciência Política encontrava-se integrado ao ativismo tardio do ISEB.

A aula inaugural do Curso Regular de 1963, proferida por Osny, pode esclarecer, em grande medida, o estado de espírito do ISEB em sua última fase. Podese compreender, mesmo dela discordando, a acusação de Guerreiro Ramos, de que o ISEB tornara-se um órgão de doutrinação marxista-leninista. O tom de Osny é inflamado, mais do que o do próprio Vieira Pinto, que, nas palavras de Jaguaribe, radicalizava sua plateia e por ela era radicalizado (PEREIRA, 2002:162). Vieira Pinto valia-se de um cabedal categorial bastante eclético, e sua inflamação era entremeada por considerações teóricas e tributos a diferentes linhagens do pensamento filosófico. O discurso de Osny é direto, sem meandros. A mensagem aos estudantes é clara: o desenvolvimentismo tradicional está esgotado, não há conciliação possível entre burguesia e proletariado nacional, e o ISEB deve colaborar diretamente na elaboração do projeto das Reformas de Base do governo João Goulart.

O nacional-desenvolvimentismo orgânico de Vieira Pinto, como já observado, comportava reformulações, e esse momento do ISEB incorpora a crítica à estrutura da sociedade brasileira em termos internos - desigualdades de terra, renda, educação, etc - e, por conseguinte, certo desencanto com setores da burguesia nacional associados à espoliação. Osny chama atenção, por exemplo, para a situação dos operários urbanos, empregados, em grande parte, em indústrias nacionais, cujos lucros anuais aumentavam muito mais do que os salários reais dos trabalhadores. É, portanto, uma guinada do nacionalismo isebiano à esquerda, o que não torna a sentença de Guerreiro Ramos necessariamente precisa, pois o intenso engajamento dessa fase se dá em torno das Reformas de Base, um plano de ações muito distante das orientações da doxa marxista - leninista. Afirma Osny que "a revoluçao está na consciência de todos os sociólogos e se muitos consideram-na viável por meios pacificos, outros entendem que somente a violência Ihes dará triunfo. Esta revolução entre nós, denomina-se reformas de base" (DUARTE PEREIRA, 1963:40). O tom de Osny é certamente ambíguo, mas não creio ser possível enxergar um abandono do nacionaldesenvolvimentismo. em prol de um programa revolucionário. A crítica de Osny é direcionada, principalmente, às políticas do plano de metas do governo JK, com sua ampla associação ao capital externo.i.

A história do ISEB confunde-se com a querela envolvendo Hélio Jaguaribe e Álvaro Vieira Pinto. Trata-se do confronto entre dois sistemas de representação - o primeiro, personificado por Jaguaribe, concebia o saber científico como coleção de especialidades autônomas na construção e exploração científica de seus objetos. A normatividade, nessa perspectiva, deve ser, se não evitada, separada do momento da análise positiva. Opõe-se, pela sua natureza, à concepção de Vieira Pinto, de um nacionalismo melífluo, de raízes existenciais, que constitui o princípio de inteligibilidade primordial das sociedades, conforme avançam na integração ao circuito do capitalismo internacional e conquistam sua independência formal. Ambos, porém, restaram unidos na má sorte que a posteridade intelectual Ihes outorgou. Cortes (2003), nesse sentido, indicou o desprezo e a repulsa provocados pela filosofia de Vieira Pinto, em particular, e pelo corpus isebiano, em geral, sobre a geração subsequente de cientistas sociais, ligados à Universidade de São Paulo, e adeptos da voga estruturalista sensivelmente infensa à "nação" como categoria válida de análise objetiva. Unidades como periferia, centro, terceiro e primeiro mundo passam a habitar o vocabulário acadêmico, e, na nação, já não se busca sua singularidade, mas suas coordenadas, sua posição estrutural no capitalismo internacional. 
A circunstância acima mencionada do passo além de Jaguaribe selou o destino do ISEB, que ao tornar-se mais e mais unido em torno das propostas de reformas estruturais, tornou-se, também, cada vez mais visível aos olhos de seus adversários ideológicos. O crescimento do ISEB é aferível pelo crescimento do número de cursos extraordinários: de apenas um em 1956 a cinco em 1960 (o ano de 1959 fora especialmente pródigo: nove cursos extraordinários), e pela diversificação de seu público-alvo, que envolve lideranças estudantis, oficiais das forças armadas, sindicalistas, e, em alguns casos até mesmo o "público" em geral.

Em abril de 1964, o ISEB torna-se vítima de seu crescimento. O apoio às reformas de base, a ampla atuação cultural junto às lideranças estudantis e a guinada à esquerda de seus intelectuais da última fase fizeram do ISEB um alvo em potencial da paranóia da subversão. A caça às bruxas promovida pelas forças militares recémvitoriosas pune o arrojo do instituto com depredações e ameaças. O ISEB é oficialmente extinto a 13 de abril, e um inquérito-policial-militar recai sobre seus membros, dando forma final à melancólica débâcle da inteligência política brasileira.

(Recebido para publicação em maio de 2018)

(Reapresentado em julho de 2018)

(Aprovado para publicação outubro de 2018)

\section{Cite este artigo}

MANO GONÇALVES, Daniel, 2018. Ciência e política, ciência ou política: O ISEB e suas duas vocações. Revista Estudos Políticos: a publicação semestral do Laboratório de Estudos Hum(e)anos (UFF). Rio de Janeiro, Vol.9 | N.2, pp. 24-41, novembro de 2018.

\section{Notas}

1. "Esta efetivação do trabalho aparece ao estado nacional-econômico como desefetivação do trabalhador, a objetivação como perda do objeto e servidão ao objeto, a apropriação como estranhamento, como alienação". (MARX, 2004:80).

2. É digna de nota a ênfase quantitativa de Osny, sempre referida, porém, a aspectos morais e políticos - "Nas escolas do Engenho de Dentro, na Guanabara, 4,3\% dos alunos tomavam leite mais de uma vez por dia; $19,4 \%$ e 76,3 \% não tomavam nunca. "p. 37. "No Brasil morre uma criança cada 42 segundos, 85 por hora e 2.040 por dia, quase todas vítimas de miséria". (DUARTE PEREIRA, 1963, p. 38). 


\section{Referências bibliográficas}

CABRAL, Manuel Villaverde. "História e Política nas Ciências Sociais Portuguesas, 1880-1980". In: LAMOUNIER, Bolivar (org.) A Ciência Política nos anos 80. Brasília: UnB, 1982, pp. 251-280.

CORBISIER, Roland. Formação e Problema da Cultura Brasileira. Rio de Janeiro: MEC/ISEB, 1959.

CORTES Norma. Esperança e democracia: as idéias de Álvaro Vieira Pinto. Rio de Janeiro: IUPERJ, 2003.

CORTES, Norma. Álvaro Vieira Pinto: "A realidade como construção dialógica e temporal". Perspectivas, 2005, vol. 28.

DUARTE PEREIRA, Osny. "O ISEB. O Desenvolvimento e as Reformas de Base". Revista Brasiliense, mai/ jun 1963, vol. 1, no 47, pp. 23-41.

FORJAZ, Maria Cećlia Spina. "A Emergência da Ciência Política no Brasil: aspectos institucionais". Revista Brasileira de Ciências Sociais, fev/1997, vol. $12, \mathrm{n}^{\circ} 35$.

GUERREIRO RAMOS, Alberto. Mito e Verdade da Revolução Brasileira. Rio de Janeiro: Zahar, 1963.

HOLANDA, Sérgio Buarque de. Raizes do Brasil. São Paulo: Companhia das Letras, 2011.

JAGUARIBE, Helio. O Nacionalismo na Atualidade Brasileira. Rio de Janeiro: MEC/ISEB, 1958.

LAMOUNIER, Bolívar. "A Ciência Política no Brasil: Roteiro para um Balanço Crítico". In: LAMOUNIER, Bolivar (org.) A Ciência Política nos anos 80. Brasília: UnB, 1982, pp. 407-433.

LESSA, Renato. "O Campo da Ciência Política no Brasil: uma aproximação construtivista". Revista Estudos Hum(e)anos, jan/2011, vol. 1, no 2, pp. 331.

MANNHEIM, Karl. Ideologia e Utopia. Rio de Janeiro: Guanabara, 1986.

MARX, Karl. Manuscritos Filosófico-Econômicos. São Paulo: Boitempo Editorial, 2004.

LINDBLOM, Charles. Political Science in the 1940 and the 1960's. In: BENDER, Thomas; SCHORSKE, Carl (eds.) American academic culture in transformation: fifty years, four disciplines. Princeton: Princeton University Press, 1998, pp. 225252. 
PÉCAUT, Daniel. Os intelectuais e a política no Brasil: entre o povo e a nação. São Paulo: Ática, 1990.

PEIRANO, Mariza. O pluralismo de Antônio Cândido. Revista Brasileira de Ciências Sociais, fev/1990, vol. 5, n 12, pp. 41-54.

PEREIRA, Alexsandro Eugenio. $O$ ISEB na perspectiva de seu tempo: Intelectuais, Política e Cultura no Brasil - 1952 - 1964. Tese de Doutorado, Ciência Política, USP, 2002.

PESSOA, Fernando. Poesias. Porto Alegre: L\&PM, 1996

PINTO, Álvaro Vieira. Ideologia e Desenvolvimento Nacional. Rio de Janeiro: MEC/ISEB, 1959.

POLANYI, Karl. A Grande Transformação. Rio de Janeiro: Elsevier, 2000.

RAMOS, Alberto Guerreiro. Mito e Verdade da Revolução Brasileira. Rio de Janeiro: Zahar, 1963.

SCHWARTZMANN, Simon. Avaliação e Perspectivas da Área de Ciência Política (CNPq). Disponível em http://www.schwartzman.org.br/simon/cpolitica.htm . Acesso em 22/02/2018.

TOLEDO, Caio Navarro de. ISEB: Fábrica de Ideologias. São Paulo: Ática, 1982.

WEBER, Max. Ciência e Política, Duas Vocações. São Paulo: Cultrix, 1996. 